\title{
PRODUÇÃO DE MUDAS DE Passiflora edulis SOB DIFERENTES SUBSTRATOS ORGÂNICOS
}

Cleberson de Sousa Ribeiro ${ }^{1}$, Alessandra Conceição de Oliveira ${ }^{1}$, Valéria Lima da Silva ${ }^{2}$, Sônia Costa França ${ }^{1}$, Rodrigo Vieira da Silva ${ }^{1}$, Juliana Ferreira Fonseca ${ }^{1}$, Toshik larley da Silva ${ }^{3}$

${ }^{1}$ Universidade do Estado de Mato de Grosso - UNEMAT, ${ }^{2}$ Universidade Estadual de Goiás - UEG, ${ }^{3}$ Universidade Federal de Viçosa - UFV. E-mail: iarley.toshik@gmail.com

\section{RESUMO}

O substrato é um dos fatores de maior importância na produção de mudas de espécies frutíferas, pois garantem as melhores condições de crescimento e estabilidade das mudas no campo. Com isso, objetivouse avaliar a produção de mudas de maracujazeiro amarelo (Passiflora edulis) com diferentes fontes e proporções de matéria orgânica. $O$ delineamento experimental foi em blocos casualizados, em esquema fatorial 3x4, com 4 repetições, sendo três fontes de matéria orgânica (solo + areia (testemunha); solo + areia + esterco bovino; solo + areia + esterco de galinha e solo + areia + húmus) e quatro proporções (1:1:0, 1:1:1, 1:1:2, 1:1:3), com 10 mudas por tratamento. Foram realizadas avaliações diárias para determinar 0 índice de velocidade de emergência e a porcentagem de emergência, e aos 60 dias após a semeadura foram avaliados: altura de planta, número de folhas, comprimento radicular, relação H/D, diâmetro do caule, massa fresca e seca das folhas, caule, raiz e total. Com isso, o substrato orgânico contendo húmus e o esterco bovino foram os que propiciaram as melhores condições para produção de mudas de maracujazeiro amarelo na proporção 1:1:1 e 1:1:2, respectivamente.

Palavras-chave: adubação; crescimento de mudas; maracujazeiro.

\section{PRODUCTION OF Passiflora edulis SEEDLINGS UNDER DIFFERENT ORGANIC SUBSTRATES}

\begin{abstract}
The substrate is one of the most important factors in the production of seedlings of fruit species, since they guarantee the best conditions of growth and stability of the seedlings in the field. The aim of this study was to evaluate the production of yellow passion fruit seedlings (Passiflora edulis) with different sources and proportions of organic matter. The experimental design was in randomized blocks, in a $3 \times 4$ factorial scheme, with 4 replicates, being three sources of organic matter (soil + sand (control), soil + sand + bovine manure, soil + sand + chicken manure and soil + sand + humus) and four ratios (1:1:0, 1:1:1, 1:1:2, 1:1:3), with 10 seedlings per treatment. Daily evaluations were performed to determine the rate of emergence and percentage of germination, and at 60 days after sowing, plant height, leaf number, root length, H/D ratio, stem diameter, fresh mass and dry leaves, stem, root and total. Thus, the organic substrate containing humus and bovine manure provided the best conditions for the production of yellow passion fruit seedlings in a ratio of $1: 1: 1$ to $1: 1: 2$, respectively.
\end{abstract}

Keywords: fertilizing; seedling growth; passion fruit.

\section{INTRODUÇÃO}

O Brasil é o terceiro maior produtor mundial de frutas, ficando atrás apenas da China e da Índia (REETZ et al., 2015). Com destaque na produção de frutas tropicais, sendo o maracujá (Passiflora edulis Sims flavicarpa Degener) uma das principais culturas produzidas (BARROS, 2011).
O maracujá é uma frutífera pertencente à família Passifloraceae e ao gênero Passiflora, originário da América Tropical e possui, aproximadamente, formado por 18 gêneros e 630 espécies, atualmente catalogadas. Cerca de 150 espécies são nativas do Brasil e mais de 60 espécies produzem frutos (FERNANDES et al., 2015). As espécies que possuem destaque 
comercialmente são o maracujá-amarelo (Passiflora edulis Sims f. flavicarpa Degener), seguido pelo maracujá-roxo (Passiflora edulis Sims) e pelo maracujá-doce (Passiflora alata Curtis).

O país com maior consumo mundial de maracujá é o Brasil, sendo consumido principalmente in natura, o que representa $60 \%$ da produção e o restante é destinado ao processamento de polpa de maracujá (MENEGOTO, 2008). O fruto do maracujá tem boa aceitação no mercado, principalmente pelas suas propriedades farmacológicas e terapêuticas e como polpas para sucos.

Com o aumento na produção e consumo dessa fruta no Brasil, tem-se exigido a produção de mudas sadias e livres de patógenos para, assim, garantir maior produção, diminuindo os custos de produção de mudas e aumentando a produção, utilizando assim insumos de baixo custo (PRADO; NATALE, 2004). Segundo Dias et al. (2007), para a produção de mudas de qualidade se faz necessário o uso de substratos de qualidade. Um substrato deve apresentar características físicas e químicas adequadas, com uma boa porosidade para facilitar a aeração facilitando a germinação e a respiração celular, com retenção de umidade adequada além de valor de $\mathrm{pH}$, melhor CTC, para assim atender as necessidades da espécie (WAGNER JUNIOR et al., 2007). O substrato a ser escolhido, deve apresentar características físicas e químicas desejáveis para um bom desenvolvimento das plantas e, além disso, disponibilidade em quantidade suficiente, próximo ao local de produção das mudas e a um baixo custo de aquisição (SEVERINO et al. 2006).

A variação química e biológica do substrato interfere diretamente na qualidade das plantas ou mudas (SILVA et al. 2011) e é muito comum o uso de dois ou mais materiais para formar agregados e facilitar a embebição das sementes e, consequentemente, a germinação, melhorando assim o desenvolvimento das plântulas (COGO et al., 2013).

Krats (2011) afirma que a porosidade do substrato é de suma importância para o crescimento das plantas, pois as raízes necessitam de espaços para efetuarem suas trocas gasosas e os microrganismos precisam de maior aeração para sobreviver no local. A aeração dos substratos é um dos mais importantes fatores envolvidos no crescimento radicular (MELLO, 2015).
De acordo com Meletti (2011), não se chegou a um padrão de substrato a ser usado na produção de mudas de maracujá. Por isso, temse testado diferentes tipos de substratos para a produção de mudas de maracujazeiro amarelo, sempre visando o aspecto econômico e a qualidade das plantas (CARVALHO et al., 2013). Substratos com menor teor de matéria orgânica resultaram em plantas com menores valores de massa seca da parte aérea e total (BARROSO et al., 2011). Para Santos et al. (2010), substratos alternativos vêm sendo estudados intensivamente, de forma a proporcionar melhores condições de desenvolvimento e formação de mudas de qualidade permitindo boa germinação e emergência das plântulas. -Diante do exposto e visando a viabilidade e qualidade da produção de mudas, objetivou-se avaliar a produção de mudas de maracujazeiro amarelo (Passiflora edulis) em diferentes fontes e proporções de matéria orgânica.

\section{MATERIAL E MÉTODOS}

O trabalho foi realizado no viveiro da Universidade do Estado de Mato Grosso (UNEMAT), Campus de Nova Xavantina, no período de 01 de janeiro a 05 de março de 2016. O município está localizado a $14^{\circ} 24^{\prime} 40^{\prime \prime} \mathrm{S}$ de latitude, $52^{\circ} 21^{\prime} 11^{\prime \prime} \mathrm{W}$ de longitude e $275 \mathrm{~m}$ de altitude. $O$ clima é do tipo Aw (clima tropical com estação seca de inverno), segundo a classificação de Köppen (KÖPPEN; GEIGER, 1928).

$O$ experimento foi instalado em esquema fatorial $3 \times 4$, sendo três tipos de matéria orgânica e quatro proporções de cada substrato no delineamento em blocos casualizados (DBC) com quatro repetições. Cada um dos 12 tratamentos foi constituído de dez plantas por parcela, totalizando 480 plantas. Os tratamentos foram os seguintes: solo + areia, testemunha para todos (1:1:0); solo + areia + esterco bovino (nas proporções $1: 1: 1 ; 1: 1: 2 ; 1: 1: 3)$; solo + areia + húmus (nas proporções 1:1:1; 1:1:2; 1:1:3), solo + areia + esterco de galinha (nas proporções 1:1:1; $1: 1: 2 ; 1: 1: 3)$.

Foi realizada análise química e física dos substratos testados no Laboratório Dalcin Serviços Agropecuários sendo determinados os teores de macronutrientes ( $\mathrm{N}, \mathrm{P}, \mathrm{K}, \mathrm{Ca}, \mathrm{Mg}$ e $\mathrm{S}$ em $\%)$ e de micronutrientes ( $\mathrm{B}, \mathrm{Cu}, \mathrm{Fe}, \mathrm{Mn}$ e $\mathrm{Zn}$ em $\left.\mathrm{mg} \mathrm{Kg}^{-1}\right), \mathrm{pH}$ e condutividade elétrica (C.E.) (Tabela 1). 
Tabela 1. Análise química, física, pH e condutividade elétrica (C.E.) dos diferentes substratos orgânicos testados.

\begin{tabular}{|c|c|c|c|c|c|c|c|c|c|c|c|}
\hline \multirow{3}{*}{$\frac{\text { Substrato }^{*}}{\text { S1 }}$} & \multicolumn{3}{|c|}{$\mathrm{pH}$} & $\mathbf{P}$ & $\mathbf{K}$ & $\mathrm{Ca}$ & \multirow{2}{*}{ IVI } & \multirow[t]{2}{*}{ Al } & \multirow{2}{*}{$\begin{array}{l}\text { M.O. } \\
\mathrm{g} \mathrm{dm}^{-3}\end{array}$} & \multirow{2}{*}{\multicolumn{2}{|c|}{$\begin{array}{c}\text { C.E. } \\
\mathrm{mS} \mathrm{cm}^{-1}\end{array}$}} \\
\hline & \multirow{2}{*}{$\begin{array}{r}\mathrm{H}_{\mathbf{2}} \mathbf{O} \\
5,9\end{array}$} & \multirow{2}{*}{\multicolumn{2}{|c|}{$\begin{array}{c}\mathrm{CaCl}_{2} \\
5,2\end{array}$}} & \multicolumn{3}{|c|}{---- $\mathrm{mg} \mathrm{dm}^{-3}$} & & & & & \\
\hline & & & & 5,9 & 41 & 1,12 & 0,5 & 0 & 6,1 & & 58,22 \\
\hline S2 & 7,9 & & 7,5 & 168,2 & 2640 & 2,43 & 1,78 & 0 & 14,4 & & 1848 \\
\hline S3 & 8,3 & & 7,8 & 260,8 & 1920 & 3,35 & 2,79 & 0 & 33,8 & & 1567 \\
\hline S4 & 9 & & 8,3 & 360,6 & 4800 & 3,41 & 2,52 & 0 & 40,6 & & 1242 \\
\hline S5 & 7,3 & & 6,3 & 181,3 & 555 & 1,68 & 1,36 & 0,1 & 12,3 & & 0,629 \\
\hline S6 & 6,1 & & 5,7 & 332,7 & 276 & 2,61 & 1,77 & 0,24 & 10,7 & & 0,427 \\
\hline S7 & 7,7 & & 7 & 454,5 & 675 & 2,33 & 1,86 & 0,28 & 10,4 & & 0,262 \\
\hline S8 & 6,9 & & 6,2 & 264,7 & 1400 & 3,59 & 3,93 & 0,05 & 41 & & 0,793 \\
\hline S9 & 7,3 & & 6,8 & 415,6 & 1800 & 4,42 & 4,67 & 0,33 & 45 & & 1100 \\
\hline S10 & 7,2 & & 6,9 & 558,1 & 2500 & 5,27 & 5,37 & 0,19 & 57,7 & & 1478 \\
\hline \multirow{2}{*}{ Substrato ${ }^{*}$} & SB & CTC & $\mathbf{v}$ & B & $\mathrm{Cu}$ & $\mathrm{Fe}$ & $M n$ & $\mathrm{Zn}$ & Argila & Silte & Areia \\
\hline & \multicolumn{2}{|c|}{$\mathrm{cmolc} \mathrm{dm}^{-3}$} & $\%$ & \multicolumn{3}{|c|}{ - $\mathrm{mg} \mathrm{dm}^{-3}$} & & $\ldots$ & \multicolumn{3}{|c|}{--------g kg ${ }^{-1}-------$} \\
\hline S1 & 1,7 & 3,9 & 43,9 & & 0,31 & 48 & 9,25 & 0,65 & 75 & 50 & 875 \\
\hline S2 & 11 & 12,1 & 90,9 & 0,278 & 0,52 & 39,12 & 25,12 & 4,91 & 75 & 50 & 875 \\
\hline S3 & 11,1 & 12,2 & 90,2 & 0,671 & 0,93 & 40,29 & 56,41 & 10,8 & 100 & 50 & 850 \\
\hline S4 & 18,2 & 18,2 & 96,8 & 1,648 & 0,74 & 47,09 & 52,19 & 12,9 & 25 & 25 & 950 \\
\hline S5 & 4,5 & 6,5 & 69 & 1,748 & 0,87 & 34,81 & 77,4 & 16,3 & 100 & 25 & 875 \\
\hline S6 & 5,1 & 7,8 & 65,3 & 1,126 & 0,88 & 56,85 & 18,94 & 8,17 & 50 & 25 & 925 \\
\hline S7 & 5,9 & 7,7 & 76,7 & 0,596 & 1,45 & 186,7 & 21,48 & 13 & 50 & 25 & 925 \\
\hline S8 & 11,1 & 13,2 & 84,1 & 0,621 & 0,75 & 42,03 & 20,28 & 4,86 & 100 & 50 & 850 \\
\hline S9 & 13,7 & 15,7 & 87,3 & 1,122 & 0,67 & 20,41 & 99,86 & 23,1 & 100 & 50 & 850 \\
\hline S10 & 17 & 19 & 89,5 & 1,673 & 0,56 & 18,28 & 114,9 & 28,6 & 100 & 50 & 850 \\
\hline
\end{tabular}

S1: Testemunha (1:1:0); S2: substrato orgânico bovino na proporção 1:1:1; S3: substrato orgânico bovino na proporção 1:1:2; S4: substrato orgânico bovino na proporção 1:1:3; S5: substrato orgânico de galinha na proporção 1:1:1; S6: substrato orgânico de galinha na proporção 1:1:2; S7: substrato orgânico de galinha na proporção 1:1:3; S8: substrato orgânico de húmus na proporção 1:1:1; S9: substrato orgânico de húmus na proporção 1:1:2; S10: substrato orgânico de húmus na proporção 1:1:3.

A semeadura foi realizada em sacos de polietileno de $14 \times 20 \mathrm{~cm}$, com capacidade para um litro de substrato, sendo semeadas três sementes por saco. Foram utilizadas sementes de maracujá da variedade Redondo Amarelo. Todos os materiais utilizados na formulação dos substratos foram peneirados e misturados nas devidas proporções. Os sacos foram dispostos em bancadas de ferro, em viveiro telado com tela de poliolefina com $50 \%$ de sombreamento. A irrigação foi realizada diariamente, o controle de plantas daninhas e pragas foi realizado manualmente. $O$ desbaste foi feito com o auxílio de uma tesoura de e quando as plântulas já estavam estabelecidas deixando apenas uma muda por saco.

A avaliação inicial das plântulas emergidas iniciou-se uma semana após a semeadura. Foram avaliadas a porcentagem de emergência e o índice de velocidade de emergência (IVE), sendo realizada diariamente a contagem considerando-se as plântulas totalmente emergidas somente as acima do substrato e com cotilédones abertos, a avaliação foi realizada até todas as plântulas estarem estabelecidas. A porcentagem de emergência foi 
calculada segundo metodologia proposta por Labouriau e Valadares (1976). Para o índice de velocidade de emergência (IVE), determinado a partir da contagem diária, adotou-se a fórmula proposta por Maguire (1962). Ao final da primeira avaliação foi realizado o desbaste deixando a planta mais vigorosa por saco.

Aos 60 dias após a semeadura, realizouse a avaliação final, onde foi analisada as seguintes variáveis: diâmetro do colo (DC), número de folhas (NF), altura da parte aérea (APA), comprimento da raiz (CR), massa fresca das folhas (MFF), do caule (MFC), da raiz (MFR) e total (MFT), massa seca das folhas (MSF), do caule (MSC), da raiz (MSR) e total (MST). A relação altura e diâmetro (H/D) foi calculada dividindo a altura pelo diâmetro, obtendo assim a relação entre os dois parâmetros.

Os dados foram submetidos à análise de variância e as médias comparadas pelo teste de Tukey ao nível de $5 \%$ de probabilidade. As análises foram realizadas pelo programa SISVAR (FERREIRA, 2011).

\section{RESULTADOS E DISCUSSÃO}

A porcentagem de emergência (\%E) e o índice de velocidade de emergência (IVE) para o substrato esterco de bovino e húmus em todas as proporções não obteve diferença significativa. Em contrapartida, o substrato esterco de galinha na \%E e IVE, a proporção 1:1:0 foi superior as demais e a proporção 1:1:3 foi a que obteve resultado inferiores (Tabela 2 ).

Tabela 2. Porcentagem de emergência (\%E) e índice de velocidade de emergência (IVE) de plantas de maracujá amarelo em função dos diferentes substratos.

\begin{tabular}{ccccccccc}
\hline & \multicolumn{7}{c}{ Proporção } \\
\cline { 2 - 8 } M.O. & \multicolumn{7}{c}{ \%E } & \multicolumn{7}{c}{ IVE } \\
\cline { 2 - 8 } & $1: 1: 0$ & $1: 1: 1$ & $1: 1: 2$ & $1: 1: 3$ & $1: 1: 0$ & $1: 1: 1$ & $1: 1: 2$ & $1: 1: 3$ \\
\hline Bovino & $72,0 \mathrm{aA}$ & $70,0 \mathrm{aA}$ & $60,0 \mathrm{aA}$ & $50,0 \mathrm{abA}$ & $2,59 \mathrm{aA}$ & $2,48 \mathrm{aA}$ & $2,51 \mathrm{aA}$ & $1,76 \mathrm{abA}$ \\
Galinha & $75,0 \mathrm{aA}$ & $55,0 \mathrm{baB}$ & $47,5 \mathrm{baB}$ & $32,50 \mathrm{bC}$ & $2,58 \mathrm{aA}$ & $1,81 \mathrm{aAB}$ & $1,28 \mathrm{bB}$ & $1,65 \mathrm{bAB}$ \\
Húmus & $70,0 \mathrm{aA}$ & $70,0 \mathrm{aA}$ & $57,50 \mathrm{aA}$ & $65,0 \mathrm{aA}$ & $2,50 \mathrm{aA}$ & $2,51 \mathrm{aA}$ & $2,79 \mathrm{aA}$ & $2,90 \mathrm{aA}$ \\
\hline
\end{tabular}

Médias seguidas de mesma letra maiúscula na linha e minúscula na coluna não diferem entre si pelo teste de Tukey a $5 \%$ de probabilidade.

Para o número de folhas (NF) notou-se que não houve diferença significativa entre as fontes de matéria orgânica, contudo, a proporção 1:1:1 diferiu das demais em todos as fontes de matéria orgânica. Observa-se que a variável altura da parte aérea (APA) mostrou diferença estatística entre a proporção 1:1:0 e as demais proporções. O substrato esterco de bovino obteve o maior valor de APA, com o valor de $70,05 \mathrm{~cm}$ na proporção 1:1:2. Na proporção 1:1:1 utilizando a matéria orgânica de esterco de galinha alcançou-se valores de $66,76 \mathrm{~cm}$ da APA (Tabela 3). Santos et al. (2011), observaram que mudas de maracujazeiro amarelo produzidas em substrato em $100 \%$ de húmus de minhoca apresentaram maiores valores para a variável altura de planta. Negreiros et al. (2005) trabalhando com diferentes substratos na produção de mudas de mamoeiro do grupo 'Solo' verificaram que $\mathrm{o}$ esterco de curral na formulação dos substratos, proporcionou os melhores resultados para a altura das mudas. 
Tabela 3. Número de folhas (NF), altura da parte aérea (APA), diâmetro do colo (DC), relação altura/diâmetro (H/D) e comprimento da raiz (CR), de planta de maracujá amarelo em função dos diferentes substratos.

\begin{tabular}{|c|c|c|c|c|c|c|c|c|}
\hline \multirow{3}{*}{ M.O. } & \multicolumn{8}{|c|}{ Proporção } \\
\hline & \multicolumn{4}{|c|}{ NF } & \multicolumn{4}{|c|}{ APA } \\
\hline & 1:1:0 & 1:1:1 & $1: 1: 2$ & 1:1:3 & 1:1:0 & 1:1:1 & $1: 1: 2$ & 1:1:3 \\
\hline Bovino & $8,55 a B$ & $12,50 \mathrm{aA}$ & $13,50 \mathrm{aA}$ & $13,00 \mathrm{aA}$ & $17,08 \mathrm{aB}$ & $57,75 a A$ & $70,05 a A$ & $63,88 \mathrm{aA}$ \\
\hline Galinha & $8,35 a B$ & $12,50 \mathrm{aA}$ & $11,50 a A$ & $12,00 \mathrm{aA}$ & $17,28 a B$ & $66,76 a A$ & $63,38 \mathrm{aA}$ & $54,07 a A$ \\
\hline \multirow[t]{2}{*}{ Húmus } & $8,75 a B$ & $11,50 \mathrm{aA}$ & $12,50 \mathrm{aA}$ & $12,00 \mathrm{aA}$ & $17,58 \mathrm{aB}$ & $56,38 \mathrm{aA}$ & $67,30 \mathrm{aA}$ & $63,05 \mathrm{aA}$ \\
\hline & \multicolumn{4}{|c|}{$\mathrm{DC}$} & \multicolumn{4}{|c|}{$H / D$} \\
\hline Bovino & $2,00 a B$ & $4,31 \mathrm{aA}$ & $4,62 \mathrm{aA}$ & $4,14 a \mathrm{~A}$ & $8,00 \mathrm{aB}$ & $13,48 a A$ & $15,15 a A$ & $15,40 a A$ \\
\hline Galinha & $2,07 a C$ & $4,44 a A$ & $4,34 \mathrm{aA}$ & $3,83 b B$ & $8,20 \mathrm{aB}$ & $14,98 \mathrm{aA}$ & $14,33 a A$ & $13,98 \mathrm{aA}$ \\
\hline \multirow[t]{3}{*}{ Húmus } & $2,17 a C$ & $4,18 \mathrm{aB}$ & $4,84 a A$ & 4,46aB & $8,17 \mathrm{aB}$ & $13,49 a A$ & $13,88 \mathrm{aA}$ & $14,16 a A$ \\
\hline & & \multicolumn{7}{|c|}{ CR } \\
\hline & & \multicolumn{2}{|c|}{ 1:1:0 } & 1:1:1 & \multicolumn{2}{|r|}{$1: 1: 2$} & \multicolumn{2}{|l|}{$1: 1: 3$} \\
\hline Bovino & & \multicolumn{2}{|c|}{$19,33 a A$} & $18,68 \mathrm{aA}$ & \multicolumn{2}{|r|}{$17,15 b A$} & \multicolumn{2}{|c|}{$16,64 \mathrm{bA}$} \\
\hline Galinha & & \multicolumn{2}{|c|}{$19,79 a A$} & $20,44 a A$ & \multicolumn{2}{|r|}{$17,33 \mathrm{bA}$} & \multicolumn{2}{|c|}{$17,66 \mathrm{bA}$} \\
\hline Húmus & & \multicolumn{2}{|c|}{$19,73 a A$} & $22,60 a A$ & \multicolumn{2}{|r|}{$21,92 \mathrm{aA}$} & \multicolumn{2}{|c|}{$24,50 \mathrm{aA}$} \\
\hline
\end{tabular}

Médias seguidas de mesma letra maiúscula na linha e minúscula na coluna não diferem entre si pelo teste de Tukey a $5 \%$ de probabilidade.

O diâmetro do colo (DC) apresentou diferença estatística apenas para a proporção 1:1:3, sendo o substrato orgânico de galinha o que apresentou resultados inferiores. Para Grave et al. (2007), o diâmetro do colo está relacionado ao maior desenvolvimento da parte aérea e ao sistema radicular, favorecendo a sobrevivência e o desenvolvimento da muda quando levada a campo.

Para a relação altura/diâmetro (H/D) observa-se que não houve diferença significativa entre as proporções com adição de substratos orgânicos (Tabela 3). Para $\circ H / D$ não foi observada diferença entre as fontes de matéria orgânica, no entanto, a concentração de 1:1:0 diferiu de todas as outras concentrações, em todas as fontes de matéria orgânica. A relação altura/diâmetro deve ter um equilíbrio, de modo que garanta a qualidade dessa muda e maio chance de pegamento quando transplantada (CAMPOS; UCHIDA, 2002). Para o comprimento de raiz $(C R)$ não foram observadas diferenças entre as concentrações de matéria orgânica, no entanto, entre as fontes desta, notou-se diferença entre o húmus e os demais nas concentrações de 1:1:2 e 1:1:3 (Tabela 3).

Para Pinto et al. (2007), as variáveis altura da parte aérea, número de folhas e diâmetro do colo são responsáveis pelas principais características para se determinar maior vigor das mudas. Rodriguez et al. (2013), trabalhando com diferentes substratos encontraram resultados semelhantes para a produção de mudas de camu-camu (Myrciaria dubia (Kunth) McVaugh), para os substratos a base de cama de frango e húmus de minhoca, com maior eficiência. Preste (2007), em trabalho com mudas de angico (Anadenanthera macrocarpa), avaliando doses crescentes de esterco bovino constatou que ao fazer adição de até $50 \%$ de esterco bovino observou-se crescimento radicular, porém com dosagem maior houve decréscimo na produção de massa radicular.

Não houve diferença entre as fontes de matéria orgânica para a variável massa fresca de folhas (MFF) (Tabela 4). Quando comparado os três substratos (para MSF) notou-se que o esterco bovino diferiu apenas do húmus na concentração 1:1:3, não diferindo do esterco de galinha. Atualmente busca-se alternativas para reduzir os custos de produção e aumentar a produção de forma sustentável. Com isso, o uso de insumos orgânicos é uma estratégia de grande valia, pois além de trazer benefícios químicos e físicos ao solo, favorece o crescimento das plantas. A adubação orgânica está em crescente uso na produção de frutíferas, dentre essas, o maracujazeiro amarelo (OLIVEIRA et al., 2018). 
Tabela 4. Massa fresca das folhas (MFF), caule (MFC), da raiz (MFR) e total (MFT) e massa seca das folhas (MSF), do caule (MSC), da raiz (MSR) e total (MSR) de planta de maracujá amarelo em função dos diferentes substratos.

\begin{tabular}{|c|c|c|c|c|c|c|c|c|}
\hline \multirow{3}{*}{ M.O. } & \multicolumn{8}{|c|}{ Proporção } \\
\hline & \multicolumn{4}{|c|}{ MFF } & \multicolumn{4}{|c|}{ MSF } \\
\hline & 1:1:0 & 1:1:1 & 1:1:2 & $1: 1: 3$ & 1:1:0 & 1:1:1 & $1: 1: 2$ & $1: 1: 3$ \\
\hline Bovino & $2,19 a C$ & $16,99 a B$ & $24,19 a A$ & $21,61 a A$ & $0,20 a B$ & $2,31 \mathrm{aA}$ & $3,62 \mathrm{aA}$ & $3,15 \mathrm{aA}$ \\
\hline Galinha & $2,39 a B$ & $22,46 \mathrm{aA}$ & 21,01aA & $17,09 a \mathrm{~A}$ & $0,19 a B$ & $3,42 \mathrm{aA}$ & $2,66 \mathrm{aA}$ & $3,35 \mathrm{aA}$ \\
\hline \multirow[t]{2}{*}{ Húmus } & $2,49 a C$ & $16,91 \mathrm{aA}$ & $20,61 \mathrm{aA}$ & $18,57 a A$ & $0,21 a B$ & $2,27 a A$ & $2,66 \mathrm{aA}$ & $1,98 \mathrm{bA}$ \\
\hline & \multicolumn{4}{|c|}{ MFC } & \multicolumn{4}{|c|}{ MSC } \\
\hline Bovino & $0,90 \mathrm{aC}$ & $6,25 a B$ & $9,35 a A$ & $7,92 a A$ & $0,20 \mathrm{aB}$ & $1,11 \mathrm{aA}$ & 1,71aA & $1,42 \mathrm{aA}$ \\
\hline Galinha & 1,02aB & $7,83 \mathrm{aA}$ & $7,03 a A$ & $5,63 \mathrm{bA}$ & $0,10 \mathrm{aB}$ & $1,30 \mathrm{aA}$ & $1,30 \mathrm{aA}$ & $0,95 \mathrm{bA}$ \\
\hline \multirow[t]{2}{*}{ Húmus } & $0,95 a \mathrm{~B}$ & $6,18 a A$ & $7,93 a A$ & $7,24 a A$ & $0,10 \mathrm{aB}$ & $1,03 a A$ & $1,40 a A$ & $1,26 a A$ \\
\hline & \multicolumn{4}{|c|}{ MFR } & \multicolumn{4}{|c|}{ MSR } \\
\hline Bovino & $1,01 \mathrm{aB}$ & $6,22 a A$ & $6,93 \mathrm{bA}$ & $5,73 \mathrm{bA}$ & $0,10 \mathrm{aB}$ & $0,72 a A$ & $0,87 \mathrm{bA}$ & $0,74 \mathrm{bA}$ \\
\hline Galinha & $1,15 \mathrm{aB}$ & $7,91 \mathrm{aA}$ & $5,25 c B$ & $3,98 \mathrm{bB}$ & $0,20 \mathrm{aB}$ & $1,0 \mathrm{aB}$ & $0,48 \mathrm{bA}$ & $0,57 \mathrm{bA}$ \\
\hline \multirow[t]{2}{*}{ Húmus } & $1,23 \mathrm{aC}$ & $8,21 a B$ & $11,17 \mathrm{aA}$ & $11,03 a A$ & $0,10 \mathrm{aC}$ & $1,0 \mathrm{aB}$ & $1,63 a A$ & $1,35 a A$ \\
\hline & \multicolumn{4}{|c|}{ MFT } & \multicolumn{4}{|c|}{ MST } \\
\hline Bovino & $4,10 \mathrm{aB}$ & $29,46 a A$ & $40,48 \mathrm{aA}$ & $35,26 a A$ & $0,50 \mathrm{aB}$ & $4,14 a A$ & $6,21 a A$ & $5,31 a A$ \\
\hline Galinha & $4,56 a \mathrm{~B}$ & $38,20 \mathrm{aA}$ & $33,29 \mathrm{bA}$ & $26,7 a A$ & $0,49 a B$ & $5,71 a A$ & $4,12 \mathrm{bA}$ & $5,22 \mathrm{aA}$ \\
\hline Húmus & $4,67 a B$ & $31,29 a A$ & $39,71 \mathrm{aA}$ & $36,8,4 a A$ & $0,41 a B$ & $4,29 a A$ & $5,69 a A$ & $4,59 \mathrm{aA}$ \\
\hline
\end{tabular}

Médias seguidas de mesma letra maiúscula na linha e minúscula na coluna não diferem entre si pelo teste de Tukey a $5 \%$ de probabilidade.

Lucena et al. (2007), trabalhando com Cassia siamea e Enterolobium maximum, ao formularem composto com solo e esterco bovino ou húmus ou esterco de galinha, nas proporções 1:1 e 2:1 (v:v), mostraram que não houve diferença estatística para massa seca da parte aérea para ambas as espécies trabalhadas nos tratamentos de esterco bovino e esterco de galinha corroborando com os dados acima citados.

Para massa fresca (MFC) e seca (MSC) do caule houve diferença estatística nas proporções de 1:1:3, respectivamente, sendo que o esterco de galinha que diferiu dos demais (Tabela 4). Quanto às proporções para a MFC adubadas com esterco bovino as concentrações de 1:1:3 e 1:1:2 não diferem entre si, mas diferem das demais. Já para as fontes de esterco de galinha e húmus todas as concentrações diferiram apenas da testemunha (1:1:0).

A matéria orgânica presente no esterco bovino e no composto orgânico, modifica positivamente as características físicas e químicas do solo, promovendo agregação de partículas elementares, aumentando a estabilidade estrutural, a permeabilidade hídrica e reduzindo a evaporação (ARAÚJO et al., 2013). Misturas de composto orgânico com areia, solo e outros substratos podem ser indicadas para produção de mudas de maracujá-amarelo (COSTA et al., 2015).

Para massa de raiz (Tabela 4), a proporção ideal de substrato esterco de bovino foi de 1:1:2, tanto para massa fresca quanto para a massa seca, já para o substrato com esterco de galinha a proporção ideal foi 1:1:1 e no substrato com húmus a proporção que obteve o resultado mais satisfatório foi de 1:1:2, quando comparados em teores de massa fresca e seca o substrato com húmus foi o que melhor se destacou, obtendo um resultado satisfatório tanto na proporção quanto para o volume encontrado. Para a massa fresca total (MFT) notou-se que só ouve diferença entre as fontes de matéria orgânica na concentração de 1:1:2, sendo que o esterco de galinha foi o menos efetivo. Entre as concentrações observou-se que todos os tratamentos diferiram da testemunha (1:1:0). Para a massa seca total (MST) houve o mesmo comportamento (Figura 4).

Santos et al. (2011), encontraram resultados satisfatórios para massa seca da raiz nas plantas submetidas ao tratamento apenas com esterco bovino. A capacidade de exploração do solo por parte das raízes depende das características químicas e físicas do solo (SILVEROL, 2014). Costa et al. (2014), observaram que quando se utilizou substratos alternativos 
obtiveram um maior comprimento de raiz e consequentemente maiores massas de raízes.

O substrato composto apenas por solo + areia se destacou somente para porcentagem de emergência sendo inferior aos demais em todas as demais variáveis avaliadas, isso pode ser explicado pelo fato que no período de germinação a semente usa a reserva acumulada e não os nutrientes do substrato. Segundo Leishman e Westoby (1994), em condições ambientais não satisfatórios as sementes usam as reservas nutricionais 0 que permite 0 estabelecimento inicial.

Para Fernandez (2002), a manutenção relativamente adequada do valor de MSR/MSPA está relacionada às melhores condições químicas e físicas dos substratos, devido à presença do esterco ou húmus em sua constituição. Malavolta et al. (2002), comentam que a vantagem no uso de tratamentos formado por resíduos orgânicos está na maior concentração de matéria orgânica.

\section{CONCLUSÃO}

O substrato orgânico contendo húmus e o esterco bovino foram os que propiciaram as melhores condições para produção de mudas de maracujazeiro amarelo na proporção 1:1:1 e 1:1:2, respectivamente.

\section{REFERÊNCIAS}

ARAÚJO, A.C.; ARAÚJO, A.C.; DANTAS, M.K.L.; PEREIRA, W.E.; ALOUFA, M.A.I. Utilização de substratos orgânicos na produção de mudas de mamoeiro Formosa. Revista Brasileira de Agroecologia, v. 8, n. 1, p. 210-216, 2013.

CAMPOS, M.A.A.; UCHIDA, T. Influência do sombreamento no crescimento de mudas de três espécies amazônicas. Pesquisa Agropecuária Brasileira, v. 37, n. 3, p. 281-288, 2002. https://doi.org/10.1590/s0100-

$\underline{204 \times 2002000300008}$

CARVALHO, R.P.; CRUZ, M.C.M.; MARTINS, L.M. Frequência de irrigação utilizando polímero hidroabsorvente na produção de mudas de maracujazeiro-amarelo. Revista Brasileira de Fruticultura, v. 35, n. 2, p. 518-526, 2013. https://doi.org/10.1590/S0100$\underline{29452013000200022}$

COGO, M.R.M.; BARBOSA, F.M.; SOUZA, L.B.; COELHO A.P.D.; FRESCURA V.D.S. Produção de mudas de Solanum betaceum cav. e Physalis angulata $\quad$ L. em diferentes substratos. Enciclopédia Biosfera, v. 9, n. 16, p. 1806-1813, 2013.

COSTA, L.A.M.; PEREIRA, D.C.; COSTA, M.S.S.M. Substratos alternativos para produção de repolho e beterraba em consórcio e monocultivo. Revista Brasileira de Engenharia Agrícola e Ambiental, v. 8, n. 2, p. 150-156, 2014. https://doi.org/10.1590/S1415$\underline{43662014000200004}$

COSTA, E.; SANTOS, L. C. R.; CARVALHO; C.; LEAL, P. A. M. Volumes de substratos comerciais, solo e composto orgânico afetando a formação de mudas de maracujazeiro-amarelo em diferentes ambientes de cultivo. Ceres, v. 58, n. 2 , p. 216 222, 2015. https://doi.org/10.1590/S0034$\underline{737 X 2011000200013}$

DIAS, T.J.; PEREIRA, W.E.; SOUSA, G.G. Fertilidade de substratos para mudas de mangabeira, contendo fibra de coco e adubados com fósforo. Acta Scientiarum Agronomia, v. 29, p. 649-658, 2007.

https://doi.org/10.4025/actasciagron.v29i5.743

FERNANDES, D.A.; ARAUJO, M.M.V.A.; CAMILI, E.C. Crescimento de plântulas de maracujazeiroamarelo sob diferentes lâminas de irrigação e uso de hidrogel. Revista de Agricultura, v. 90, n. 3, p. 229-236, 2015.

FERNANDEZ, J.R.C. Efeito de substratos, recipientes e adubação na formação de mudas de mangabeira (Hancornia speciosa Gomes). 2002. 65f. Dissertação (Mestrado em Agronomia) - Faculdade de Agronomia e Medicina Veterinária, Cuiabá, 2002.

FERREIRA, D.F. Sisvar: a computer statistical analysis system. Ciência e agrotecnologia, v. 35, n. $6, \quad$ p. 1039-1042, 2011. http://dx.doi.org/10.1590/S1413$\underline{70542011000600001}$

GRAVE, F.; FRANCO, E.T.H.; PACHECO, J.P.; SANTOS, S.R. Crescimento de plantas jovens de Açoitacavalo em quatro diferentes substratos. Ciência Florestal, v. 17, n. 4, p. 289-298, 2007. https://doi.org/10.5902/198050981961

KRATS, D. Substratos renováveis na produção de mudas de Eucalyptus benthamii Maiden et 
Cambage e Mimosa scabrella Benth. 2011. 121f. Dissertação (Mestrado em Engenharia Florestal) Setor de Ciências Agrárias, Universidade Federal do Paraná, Curitiba, 2011.

KÖPPEN, W.; GEIGER, R. Klimate der Erde. Gotha: Verlag Justus Perthes, 1928.

LABOURIAU, L.G.; VALADARES, M.E.B. On the germination of seeds Calotropis procera (Ait.) Ait.f. Anais da Academia Brasileira de Ciências, v. 48, n. 2, p. 263-284, 1976.

LEISHMAN, M.R; WESTOBY, M. The role of large seed size in shaded conditions: experimental evidence. Functional Ecology, p. 205-214, 1994. https://doi.org/10.2307/2389903

LUCENA, A.M.A.; CHAVES, L.H.G.; GUERRA, H.O.C. Desenvolvimento de mudas de cássia e tamboril em diferentes composições de substratos. Revista Verde de Agroecologia e Desenvolvimento Sustentável, v. 2, n. 1, p. 7884, 2007.

MAGUIRE, J.D. Speed of gerrnination - aid in selection and evaluation for seedling emergence and vigor. Crop Science, v. 2, n. 2, p. 176-177, 1962.

https://doi.org/10.2135/cropsci1962.0011183X0 $\underline{00200020033 x}$

MALAVOLTA, E.; GOMES, P.F.; ALCARDE, J.C. Adubos e adubações. São Paulo: Nobel, 2002.

MELETTI, L.M.M., Avanços na fruticultura tropical no Brasil. Revista Brasileira de Fruticultura, v. 33, n. $1, \quad$ p. 73-75, 2011. https://doi.org/10.1590/S0100-

29452011000500010

MELLO, T. Resíduos in natura na composição de substratos para produção de mudas de Schinus terebinthifolius Raddi. 2015. 41f. Monografia (Especialização) - Curso de Engenheiro Florestal, Centro de Ciências Agrárias Departamento de Ciências Florestais e da Madeira, Universidade Federal do Espírito Santo, Vitória, 2015.

NEGREIROS, J.R.S.; BRAGA, L.R.; ÁLVARES, V.S.; BRUCKNER, C.H. Diferentes substratos na formação de mudas de mamoeiro do grupo solo. Revista Brasileira de Agrociência, v. 11, n. 1, p. 101-103, 2005.
OLIVEIRA, F. Í. F.; DE MEDEIROS, W. J. F.; CAVALCANTE, L. F.; CAVALCANTE, Í. H. L.; LUNA SOUTO, A. G.; LIMA NETO, A. J. Crescimento e produção do maracujazeiro amarelo fertirrigado com esterco bovino líquido fermentado. Agropecuária Técnica, v. 38, n. 4, p. 191-199, 2018. https://doi.org/10.25066/agrotec.v38i4.34434

PINTO, J.L.B.; TAVARES, J.C.; ALMEIDA NETO, A.J.; FREITAS, R.S.; RODRIGUES, G.S.O. Efeito de diferentes substratos na produção de mudas de goiabeira. Revista Verde de Agroecologia e Desenvolvimento Sustentável, v. 2, n. 1, p. 127134, 2007.

PRADO, R.M.; NATALE, W. Efeitos da aplicação da escória de siderurgia ferrocromo no solo, no estado nutricional e na produção de matéria seca de mudas de maracujazeiro. Revista Brasileira de Fruticultura, v. 26, n. 1, p. 140-144, 2004. https://doi.org/10.1590/\$0100-

$\underline{29452004000100038}$

REETZ, E.R.; KIST, B.B.; SANTOS, C.E.; CARVALHO, C.; DRUM, M. Anuário Brasileiro da Fruticultura. Santa Cruz do Sul: Editora Gazeta Santa Cruz. 2015.

RODRIGUEZ, C.A.; CHAGAS, E.A.; PANDURO, M.P.; SORIA, D.G.; SANCHEZ-CHOY, J.; LOZANO, R.B.; RIOS, G.S. Production of camu-camu plants with different organic substrates in conventional nursery bed. Scientia Agropecuaria, p. 321-324, 2013. https://10.17268/sci.agropecu.2013.04.06

SANTOS, M.R.; SEDIYAMA, M.A.N.; SALGADO, L.T.; REIGADO, F.R. Production of sweet pepper seedlings in substrates containing vermicompost. Bioscience Journal, v. 26, n. 4, p. 572-578, 2010.

SANTOS, P.C.; LOPES, L.C.; FREITAS, S.J.; SOUSA, L.B.; Carvalho, A.J.C. Crescimento inicial e teor nutricional do maracujazeiro amarelo submetido à adubação com diferentes fontes nitrogenadas. Revista Brasileira de Fruticultura, v. $33, \quad$ n. $1, \quad$ p. $722-728,2011$. https://doi.org/10.1590/S0100$\underline{29452011000500101}$

SEVERINO, L.S.; LIMA, R.L.S.; BELTRÃO, N.E.M. Composição química de onze materiais 
orgânicos utilizados em substratos para produção de mudas. Campina Grande: Ministério da Agricultura Pecuária e Abastecimento, 2006. (Comunicado Técnico; 278).

SILVA, E.A.; OLIVEIRA, A.C.; MENDONÇA, V.; SOARES, F.M. Substratos na produção de mudas de mangabeira em tubetes. Pesquisa Agropecuária Tropical, v. 41, n. 2, p. 279-285, 2011. https://doi.org/10.5216/pat.v41i2.9042

SILVEROL, A.C. O solo: características físicas, químicas e a importância dos macronutrientes, micronutrientes e elementos essenciais na fertilidade do solo, com ênfase no fósforo. Parte I: Características físicas e químicas. Conhecimento em Destaque, v. 3, n. 2, p. 1-14, 2014.

WAGNER JÚNIOR, A.; SANTOS, C.E.M.; ALEXANDRE, R.S; SILVA, J.O.C; NEGREIROS, J.R.S.; PIMENTEL, L.D.; ALVARES, V.S.; BRUCKENER, C.H. Efeito da pré-embebição das sementes e do substrato na germinação e no desenvolvimento inicial do maracujazeiro-doce. Revista Ceres, v. 54, p. 1-6, 2007.

Recebido para publicação em 01/05/2018

Revisado em 04/07/2018

Aceito em 18/08/2018 